\title{
PRÁTICAS PEDAGÓGICAS DE PROFESSORES DA EDUCAÇÃO DE PESSOAS JOVENS E ADULTAS NO CAMPO: O QUE DIZEM AS TESES E AS DISSERTAÇÕES NO BRASIL (2010-2019)
}

\author{
Samuel Pires Melo ${ }^{1}$ \\ Ruth Sousa Batista ${ }^{2}$ \\ Millena Araújo de Souza ${ }^{3}$
}

\section{RESUMO}

A educação do/no campo tem se diferenciado da educação rural em seus processos socioeducativos. Os movimentos sociais têm reivindicado a educação preocupada com o desenvolvimento de seus territórios rurais, e não para o interesse estrito do Capital. Entende-se, assim, que as práticas pedagógicas dos professores se distinguem diante de seus espaços de atuação, como tem sido na Educação de Pessoas Jovens e Adultas (EPJA) em territórios rurais com turmas multisseriadas. Observam-se diferentes demandas ao educador, além da compreensão de que a escola, no seu papel de formação de sujeitos socioculturais, deve estar firmada no objetivo de desenvolver práticas pedagógicas que contribuam para o desenvolvimento de educandos autônomos. Diante disso, busca-se analisar as práticas pedagógicas dos educadores que atuam na educação de pessoas jovens e adultas no campo, por meio das teses e dissertações dos programas de pós-graduação do Brasil. Optou-se por uma pesquisa qualitativa do tipo Estado da Arte, e pela técnica de Análise Conteúdo, de Bardin (2004). Por meio dos filtros de seleção (descritores e recorte

\footnotetext{
${ }^{1}$ Doutor em Sociologia pela Universidade Federal de Pernambuco. Professor do Programa de pós-graduação em Sociologia da Universidade Federal do Piauí/ Departamento de Ciências Sociais da Educação da Universidade Federal do Delta do Parnaíba. ORCID: http://orcid.org/0000-0003-0655-2917 E-mail: samuelmelo@ufpi.edu.br.

${ }_{2}^{2}$ Pedagoga pela Universidade Federal do Delta do Parnaíba. ORCID: https://orcid.org/00000002-8450-6468. E-mail: ruthsousab08@gmail.com.

${ }^{3}$ Pedagoga pela Universidade Federal do Delta do Parnaíba. ORCID: https://orcid.org/00000002-8621-141X. E-mail: millenaraujophb@gmail.com
} 
temporal), foram encontrados seis trabalhos na Biblioteca Digital Brasileira de Teses e Dissertações, nos quais se observou que as práticas pedagógicas dos docentes da EPJA territórios rurais são marcadas por influências econômicas, culturais, políticas e sociais, que necessitam de apoio na Formação Continuada e de recursos para atuação do educador na Educação do/no campo, portanto, a partir de práticas críticas, reflexivas e integrantes das realidades que ensejam transformadoras nas salas da Educação de Pessoas Jovens e Adultas do Campo.

Palavras-chave: Educação do campo; Educação de Pessoas Jovens e Adultas; Práticas Pedagógicas.

\section{PEDAGOGICAL PRACTICES OF YOUTH AND ADULT EDUCATION TEACHERS IN THE FIELD: WHAT DO THESES AND DISSERTATIONS SAY IN BRAZIL (2010-2019)}

\section{ABSTRACT}

Abstract: The education of/in the countryside has been different from rural education in its socio-educational processes. Social movements have demanded education concerned with the development of their rural territories, and not for the strict interest of Capital. It is understood, therefore, that the pedagogical practices of teachers are distinguished in relation to their spaces of action, as it has been in the Education of Young and Adult People (EPJA) in rural territories with multigrade classes. There are different demands on the educator, in addition to the understanding that the school, in its role of training sociocultural subjects, must be based on the objective of developing pedagogical practices that contribute to the development of autonomous students. Therefore, we seek to analyze the pedagogical practices of educators who work in the education of young and adult people in the countryside, through thesis and dissertations of postgraduate programs in Brazil. We opted for qualitative research of the State-of-the-Art type, and for the Content Analysis technique, by Bardin (2004). Through selection filters (descriptors and time frame), six works were found in the Brazilian Digital Library of Theses and 
Dissertations, in which it was observed that the pedagogical practices of EPJA teachers in rural territories are marked by economic, cultural, political and social, which need support in Continuing Education and resources for the educator's performance in Education of/in the countryside, therefore, from critical, reflective practices that are part of the transformative realities in the Education of Young and Adult People in the countryside.

Keywords: Rural education; Youth and Adult Education; Pedagogical practices.

\section{PRÁCTICAS PEDAGÓGICAS DE PROFESORES DE EDUCACIÓN DE JÓVENES Y ADULTOS EN EL ÁMBITO: QUÉ DICEN LAS TESIS Y DISERTACIONES EN BRASIL (2010-2019)}

\section{RESUMEN}

La educación del / en el campo ha sido diferente a la educación rural en sus procesos socioeducativos. Los movimientos sociales han reclamado una educación preocupada por el desarrollo de sus territorios rurales, y no por el estricto interés del Capital. Se entiende, por tanto, que las prácticas pedagógicas de los docentes se distinguen en relación a sus espacios de acción, como ha sido en la Educación de Jóvenes y Adultos (EPJA) en territorios rurales con clases multigrado. Existen diferentes demandas al educador, además de entender que la escuela, en su rol de formación de sujetos socioculturales, debe basarse en el objetivo de desarrollar prácticas pedagógicas que contribuyan al desarrollo de estudiantes autónomos. Por lo tanto, buscamos analizar las prácticas pedagógicas de los educadores que trabajan en la educación de jóvenes y adultos en el campo, a través de tesis y disertaciones de programas de posgrado en Brasil. Se optó por una investigación cualitativa del tipo State of the Art, y por la técnica de Análisis de Contenidos, de Bardin (2004). A través de filtros de selección (descriptores y marco temporal), se encontraron seis trabajos en la Biblioteca Digital Brasileña de Tesis y Disertaciones, en los cuales se observó que las prácticas pedagógicas de los docentes de EPJA en territorios rurales 
están marcadas por factores económicos, culturales, políticos y sociales, que necesitan apoyo en Educación Continuada y recursos para el desempeño del educador en Educación del / en el campo, por tanto, a partir de prácticas críticas y reflexivas que son parte de las realidades transformadoras en la Educación de Jóvenes y Adultos en el campo.

Palabras clave: Educación rural; Educación de jóvenes y adultos; Prácticas pedagógicas.

\section{INTRODUÇÃO}

A educação "no" e "do" campo se diferencia da educação rural, porque se constitui como abordagem reflexiva da realidade camponesa, do modo de viver e trabalhar dos campesinos, e tem como objetivo educar para o desenvolvimento do e no campo, e não para os interesses estritos do capital. Arroyo, Caldart e Molina (2008) e Caldart (2011) retratam essa importância de educação específica no e para o campo, que respeite os saberes e os valores locais principalmente diante da taxa de analfabetismo agregada do Brasil, que, em 2010 , foi de $10,2 \%$, mas com $7,54 \%$ de analfabetos no meio urbano e $24,64 \%$ no meio rural (IPEA, 2013).

Com a taxa de analfabetismo da população rural, propagamse trajetórias de migrações e/ou afastamento dessas pessoas das escolas formais. Destaca-se, ainda, que os territórios rurais brasileiros passam por processo de nucleação das pequenas escolas rurais, com o fechamento, entre 1997 e 2018, de quase 80 mil escolas de ensino da Educação Básica, segundo um levantamento atualizado com base nos dados do Instituto Nacional de Estudos e Pesquisas Educacionais Anísio Teixeira (INEP, 2019).

Por essa perspectiva, é possível verificar também que muitos professores que têm atuado em escolas rurais são vítimas de gestão educacional precarizada e que desvaloriza o seu trabalho, destacando-se, por exemplo, o currículo descontextualizado, a desestruturação didático-metodológica, a falta de recursos financeiros para melhorar as condições da ação educativa e diversas 
outras dificuldades do magistério em uma realidade desfavorecida e em uma modalidade de educação na qual os desafios são muitos.

Diante dessa problemática, este artigo tem o objetivo de analisar como as práticas pedagógicas na Educação de Pessoas Jovens e Adultas no campo são evidenciadas nas teses e nas dissertações dos últimos dez anos (2010-2019), buscando evidenciar o tipo de educação que ocorre nesses espaços, bem como as estratégias utilizadas pelos educadores para ultrapassar as dificuldades que permeiam tal realidade.

Optou-se, para isso, por uma pesquisa com abordagem qualitativa do tipo Estado da Arte, desde a seleção dos trabalhos (por meio de descritores) à classificação e à análise das teses e das dissertações. Sobre essa última fase, seguiu-se a técnica de Bardin (2004), da análise de conteúdo, de forma a contribuir com o alcance do objetivo do trabalho, com a descrição geral das teses e das dissertações apresentadas, chegando às principais reflexões suscitadas sobre as práticas dos professores da Educação de Pessoas Jovens e Adultas (EPJA).

Foram encontrados seis trabalhos na Biblioteca Digital Brasileira de Teses e Dissertações, em que se observou que as práticas pedagógicas dos docentes da EPJA nos territórios rurais são marcadas por influências econômicas, culturais, políticas e sociais que necessitam de apoio na Formação Continuada e de recursos para a atuação do educador. Portanto, encontram-se sob a necessidade de práticas críticas, reflexivas e integrantes das realidades "que ensejam transformadoras" as salas da Educação de Pessoas Jovens e Adultas do Campo.

\section{SITUANDO O DEBATE SOBRE PRÁTICAS PEDAGÓGICAS NA EDUCAÇÃO DE PESSOAS JOVENS E ADULTAS DA EDUCAÇÃO DO/NO CAMPO}

\section{Educação de Pessoas Jovens e Adultas na Educação do Campo}

Entende-se que a educação pode se tornar lócus de construção, formação, transformação e libertação, com intuitos e 
necessidades diferentes. Assim sendo, as pessoas jovens, adultas e idosas que trabalham e vivem no campo - caracterizando-se como seres sociais que, por circunstâncias econômicas, sociais, políticas e pessoais, deixaram a escolaridade na faixa etária dita como ideal encontram-se com a EPJA, na atualidade, sob diversas perspectivas, dentre as quais a de crescer, mudar e/ou se reconfigurar na realidade em que se encontram.

Quando se evidenciam essas diversas concepções, salienta-se a complexidade com que as ruralidades e os processos educativos foram se constituindo. Para se ter uma ideia, há algumas décadas a educação rural foi se mostrando inadequada justamente porque estava inserida em paradigmas como, por exemplo, o do campo como sendo um lugar de atraso, onde essas pessoas eram ensinadas a acreditar que a vida seria melhor se fosse na cidade, configurandose de um modo muito parecido com o modelo de educação que era colocado na cidade.

A Educação do Campo surge, por outro lado, como um novo paradigma que coloca os povos do campo (crianças, jovens, adultos e idosos) em posição de protagonismo da sua própria história. Temse com ela um mecanismo de transformação social importante, e é por isso que se fala muito nos cursos de Licenciatura em Educação do Campo para a formação dos professores para atuarem nas escolas do campo.

O Conselho Nacional de Educação define que as práticas da Educação do Campo se configuram como

[...] toda ação educativa desenvolvida junto às populações do campo e fundamentam-se nas práticas sociais constitutivas dessas populações, os seus conhecimentos, habilidades, sentimentos, valores, modo de ser, de viver e de produzir, e formas de compartilhar a vida. (BRASIL, 2002).

O reconhecimento, pelo Estado, dessa modalidade de educação aconteceu pela luta dos movimentos sociais, principalmente o Movimento Sem Terra (MST). Segundo Ghedin (2012), o MST, desde 1984, tem levantado preocupações sobre o 
modo como os educandos assentados podem participar de uma educação adequada à sua realidade.

O cenário educacional brasileiro tem se mostrado cada vez mais desafiador, o que leva professores e gestão escolar a pensarem e repensarem suas práticas, criando alternativas que possibilitem a inserção efetiva e ativa dos discentes no âmbito educacional. Com o educador do campo não é diferente, pois trabalhar a Educação do Campo, para o campo e no campo exige do educador a compreensão, a participação e a vivência com a cultura desse ambiente. Monteiro (2014) fala sobre a prática da escuta como um dos pilares da prática efetiva do educador do campo.

Nesse cenário, destaca-se a EPJA. Ela é uma modalidade de ensino presente no Brasil, destinada a pessoas jovens e adultas que, por algum motivo, não conseguiram estudar na idade "regular" e que, da mesma forma, não tiveram oportunidade de acesso ao Ensino Fundamental ou Médio na idade adequada. Segundo a Lei de Diretrizes e Base da Educação Nacional (LDBEN, 9393/1996, em seu artigo $37^{\circ}$, parágrafo $1^{\circ}$,

Os sistemas de ensino assegurarão gratuitamente aos jovens e aos adultos, que não puderam efetuar os estudos na idade regular, oportunidades educacionais apropriadas, consideradas as características do alunado, seus interesses, condições de vida e de trabalho mediante cursos e exames. (BRASIL, 1996)

A EPJA passou por diversas mudanças, acompanhando as alterações do cenário político. Pode-se abordar que as ações governamentais ainda têm muito que trabalhar na modalidade da Educação de Pessoas Jovens e Adultas para atender às expectativas e às necessidades dos estudantes. "[...] Muitos jovens e adultos de hoje viram esse direito negado na chamada 'idade própria' e negar uma nova oportunidade a eles é negar-lhes, pela segunda vez, o direito à educação." (GADOTTI, 2013, p. 19).

Para que se tenha uma ideia das ações governamentais, na década de 1960, durante o regime militar, destacou-se o surgimento do Movimento Brasileiro de Alfabetização (MOBRAL). Esse 
Movimento tinha como finalidade erradicar o analfabetismo da população mais pobre, mas não levava em consideração os conhecimentos prévios dos alunos.

Os educadores criticavam os métodos de alfabetização utilizados, dizendo que os mesmos, produziam males; que os alunos voltariam a ser analfabetos e que o governo não queria educar nenhum indivíduo. Porém, o Mobral também foi muito reconhecido com alguns prêmios, entre eles o Prêmio Mohammad Reza Pahlavi, outorgado pela UNESCO em 1973; o Prêmio Internacional Iraque de Alfabetização, de 1982; a Menção Honrosa, pela Associação Internacional para a Leitura da UNESCO, em 1983. (BELUZO; TONIOSO, 2015, p. 202).

Com o passar dos tempos, os objetivos do MOBRAL foram modificados, mas o Movimento foi extinto no ano de 1985. Por outro lado, em 2003, outro programa foi criado. Segundo Beluzo e Tonioso (2015, p. 206), no citado ano,

[...] durante o governo de Luís Inácio Lula da Silva, desenvolveu-se O PBA - Programa Brasil Alfabetizado, cujo objetivo principal era superar o analfabetismo, que abrangia jovens e adultos, contribuindo assim para a universalização do ensino fundamental no Brasil.

Apesar dos objetivos do PBA, suas metas não foram atingidas no período programado, tendo, assim, a necessidade de reorganização. No entanto, cabe ressaltar que o Programa mostrou que a educação não é obrigação apenas do Estado, mas também de toda a população. Na verdade, a EPJA "[...] é apontada como uma modalidade fulcral para a construção de um projeto de sociedade inclusiva e democrática" (FREITAS; BICCAS, 2009, p. 3).

Quando se destaca a relação entre Educação do Campo e EPJA, é possível situar a educação como constituinte da prática social e histórica que se liga diretamente à vida objetiva e subjetiva dos sujeitos envolvidos, ou seja, a educação é uma prática social e histórica que se liga à vida pessoal de cada indivíduo em seus grupos 
sociais (THERRIEN, 1993). Além disso, para a efetivação da Educação do Campo que atenda às especificidades dos indivíduos do meio rural, é necessário maior apoio educacional vindo das políticas educacionais.

Para Arroyo (2007), as políticas educacionais do Brasil se constituem de uma indefinição de rumos, principalmente quando se trata da Educação do Campo. Para o autor, as escolas rurais são tratadas como se fossem resíduos do sistema educacional, de modo que a essa população foram negados os avanços que nasceram nas últimas décadas da garantia do direito ao acesso à Educação Básica não somente o acesso à educação, mas também a condições educacionais adequadas.

Nessas análises, o Estado não é o problema. Pode ser criticado por não ser igualitário na solução dos problemas sociais, por dar maior atenção e mais recursos a uns setores da sociedade do que a outros. O apelo será para que o Estado seja equitativo na função de alocar recursos para solucionar os problemas da sociedade, que as políticas públicas que sejam distributivas; que diante das desigualdades o estado implemente como solução políticas compensatórias para os mais desiguais. (ARROYO, 2007, p. 387).

A formação do educador do campo por parte do Estado também está inserida na construção da Educação do Campo, pois esse profissional será capaz de contribuir para o reconhecimento da identidade do alunado como sujeito das ruralidades brasileiras. Desse modo, faz-se de extrema importância um educador com formação voltada ao campo. É necessário refletir acerca de como está acontecendo a formação do educando do campo, visto que o Estado, muitas vezes, não possibilita ao educador as condições necessárias para a Educação do Campo alinhada às suas especificidades.

A história nos mostra que não temos uma tradição nem na formulação de políticas públicas, nem no pensamento e na prática de formação de profissionais da educação que focalize a educação do campo e a formação de educadores do campo 
como preocupação legítima. (ARROYO, 2007, p. 158).

Percebe-se que a formação voltada aos profissionais da Educação do Campo ficou fora do contexto histórico da educação brasileira. Isso desfavorece, segundo Freire (1997), a ação-reflexãoação, principalmente porque, "[...] na formação permanente dos professores, o momento fundamental é o da reflexão crítica sobre a prática. É pensando criticamente a prática de ontem que se pode melhorar a próxima prática." (p. 18).

A Educação do Campo não pode ter sua formação educacional baseada na formação educacional urbana, pois o sujeito do campo, muitas vezes, busca a educação que se adeque à sua realidade. Desse modo, na sua formação, o educador deve compreender as experiências dessas pessoas, de modo que o seu processo formativo precisa ter base teórica que o possibilite avançar na relação com o ser professor. Sheibe (2010) afirma que falta formação sólida e cultural que permita ao educador ir além do conteúdo pedagógico.

\section{Práticas pedagógicas de professores da EPJA na Educação do Campo}

Veiga (1992, p. 16) afirma que a prática pedagógica é "[...] uma prática social orientada por objetivos, finalidades e conhecimentos, e inserida no contexto da prática social. A prática pedagógica é uma dimensão da prática social [...]". Sendo assim, compreende-se que a prática pedagógica é intrínseca ao contexto social da realidade em que se atua, tendo seus objetivos, suas finalidades e seus conhecimentos voltados para a prática social, assim contribuindo para o pleno desenvolvimento da pessoa jovem e adulta no/do campo. Para Freire (1997, p. 12), ensinar "[...] não é transferir conhecimento, mas criar as possibilidades para sua produção ou a sua construção". Nesse sentido, "É na troca de saberes entre educandos e educadores e na reflexão e ação sobre a realidade em que vivem que o conhecimento é construído." (ZANETTI; SCHWENDLER, 2003, p. 15). 
Entende-se, portanto, que a prática pedagógica dos educadores do campo não deve se dar apenas como processamento de conteúdos desvinculados da realidade dos educandos; deve, porém, ser refletida na sua ação, para que, como Freire ressalta em suas obras, o conhecimento seja significativo. As experiências e os saberes das pessoas jovens e adultas devem ser considerados e valorizados no processo de planejamento, ensino e avaliação - sendo assim, no ensino-aprendizagem. Britto (2003, p. 24) pontua um aspecto importante sobre a EPJA:

\begin{abstract}
A educação de adultos não deve ser pensada como um processo de recuperação de algo que tenha sido perdido ou não aprendido no momento adequado. Tampouco deve seguir os mesmos critérios e referenciais da educação regular de crianças e adolescentes. $\mathrm{O}$ adulto não volta para a escola para aprender o que deveria ter aprendido quando criança e não aprendeu. Ele busca a escola para aprender habilidades necessárias para ele no momento atual.
\end{abstract}

O que o autor salienta é interessante para a reflexão, pois, em uma sala de aula multisseriada constituída por pessoas jovens e adultas, com diferentes habilidades, necessidades e níveis de aprendizagens, no que corresponde à ação docente, pontua-se uma grande dificuldade, por haver a necessidade de abordagens diferenciadas em sua prática pedagógica, acarretando sobrecarga na atividade docente e na mediação de conhecimentos para cada caso. Codo (1999, p. 85) confirma tal reflexão ao afirmar:

[...] quanto maior a defasagem entre o "trabalho como deve ser" e a "realidade do trabalho" nas escolas, maior será o investimento afetivo e cognitivo exigido ao professor, maior será o esforço realizado e por isso, maior será seu sofrimento no cotidiano do trabalho.

Evidencia-se a dicotomia entre a teoria e a prática, resultante de dificuldades apresentadas pelos contextos, pelo currículo e pela falta de recursos financeiros. Portanto, percebe-se que a ação 
educativa na Educação de Pessoas Jovens e Adultas no campo, em que, na maioria das vezes, atua-se em salas multisseriadas, é um trabalho árduo e com progressos lentos. Perceber essa realidade é de grande valia, principalmente pela importância de se estudar a prática pedagógica dos professores na EPJA no campo, já que essa se caracteriza como uma modalidade de ensino que se dá em contexto social, econômico e político historicamente defasado e desvalorizado, de modo que é preciso perceber as nuanças que ocorrem na práxis docente e os seus desdobramentos diante dos conflitos que se dão no processo.

Segundo Leal et al. (2007), é fundamental que o professor se sinta desafiado a repensar o tempo pedagógico, analisando se ensina o que é de direito para os estudantes e se a seleção dos conteúdos, das capacidades e das habilidades é, de fato, importante naquele momento, considerando que educandos apresentam características singulares nessas etapas de desenvolvimento. Partindo desse pensamento, a prática pedagógica, de forma que alcance os objetivos de desenvolvimentos propostos para as pessoas jovens e adultas, requer que os professores repensem e selecionem seus conteúdos, atentando à dimensão cognitiva dos educandos, abrangendo em suas aulas os conhecimentos que terão significado de aprendizagem para o alunado, e possibilitando, então, que a prática pedagógica seja de valia, para que se chegue às metas traçadas quanto ao bom desenvolvimento cognitivo, afetivo, social e cultural dos alunos da EPJA. Nesse sentido,

O que define o professor não é a aula, mas a habilidade de aprender em seu campo profissional, seguida da habilidade de fazer o aluno aprender. Temos professores com titulação máxima e que aprendem pouco e não se interessam pela aprendizagem dos alunos. Só dão aula, daquelas tipicamente reprodutivas (DEMO, 2004, p. 73).

O aprender do professor, segundo Demo (2004), diz respeito à sua reflexão-ação na prática, que faz e refaz caminhos para proporcionar um espaço de aprendizagem significativo, sob o compromisso que o professor deve ter para que os alunos tenham 
uma prática pedagógica de qualidade, de modo que as aulas não sejam levadas pelo comodismo e pelo mecanicismo pedagógico. Isso se torna um desafio na Educação de Pessoas Jovens e Adultas do Campo.

\section{ASPECTOS METODOLÓGICOS}

Optou-se, neste estudo, pela pesquisa qualitativa (LÜDKE, M.; ANDRÉ, 1986), que se caracteriza pelo seu caráter construtivo, interpretativo e dialógico e pela sua atenção ao estudo dos casos singulares. Utiliza-se, assim, de teses e dissertações defendidas nos Programas de Pós-Graduação em Educação Brasileira, no período de 2010 a 2019, a fim de que se realize o Estado da Arte sobre práticas pedagógicas na modalidade da EPJA no campo.

A relação entre pesquisa qualitativa e Estado da Arte se dá por meio de revisão bibliográfica acerca da produção de determinada temática em uma área de conhecimento específica. Segundo Ferreira (2002) e Romanowki e Ens (2006), esse método faz um levantamento, um mapeamento e uma análise do que se produz, considerando as áreas de conhecimento, os períodos cronológicos, os espaços, as formas e as condições de produção. Ressalta-se a pouca produção realizada nesse formato de metodologia de pesquisa, como afirma Melo (2006). Para ele, apesar dessa relevância, ainda há poucos autores e pesquisadores que se dedicam à realização de amplas pesquisas do tipo Estado da Arte e, menos ainda, que escrevem e teorizam sobre esse tipo de pesquisa.

Nessa perspectiva de pesquisa, foram feitas a escolha, o mapeamento e a discussão das teses e das dissertações sobre o tema delineado, para que se possa analisá-lo e compreendê-lo no intuito de contribuir para a produção de novos paradigmas e conceitos, novas visões e reflexões no campo teórico da área e buscando estimular a produção de pesquisas e posicionamentos para o campo de estudo. Tal trabalho foi feito mediante as seguintes fases:

- Escolha de teses e dissertações sobre práticas pedagógicas na modalidade EPJA no campo, no período de 2010 a 2019, defendidas nos Programas de Pós-Graduação em Educação Brasileira, de acordo 
com os descritores: Prática Pedagógica, Educação de Jovens e Adultos, Educação de Pessoas Jovens e Adultas e Educação no Campo;

- Coleta do material de pesquisa, eleito junto à Biblioteca Digital Brasileira de Teses e Dissertações (https://bdtd.ibict.br/vufind/);

- Leitura dos resumos das teses e das dissertações sobre práticas pedagógicas de professores da EPJA no Campo, passando, depois, à leitura das teses e das dissertações para a criação de sínteses, a fim de constituir base para a análise, considerando o tema, os objetivos, as problemáticas, as conclusões, bem como as práticas dos professores de EPJA no campo apresentadas pelo pesquisador;

- Sistematização dos temas levantados, identificando as categorias e observando as semelhanças e as diferenças em uma análise comparativa das teses e das dissertações;

- Análise e elaboração das conclusões preliminares.

Para tanto, utilizou-se a técnica de análise de conteúdo, de Bardin (2004), de forma a possibilitar o tratamento das informações, contribuindo para a análise sistemática dos textos pesquisados, ultrapassando as incertezas e refletindo sobre problemáticas e temas em produções já publicadas para o desenvolvimento de novas abordagens.

$\mathrm{Na}$ consulta à Biblioteca Digital Brasileira de Teses e Dissertações, utilizaram-se como palavras-chave: "prática pedagógica", "educação no campo", "educação do campo", "EJA" e "EPJA", resultando em 114 trabalhos. Entretanto, apesar de se constituírem importantes, foram selecionadas aquelas que se enquadravam no tema de pesquisa.

Por meio dessa seleção, observaram-se os resumos de dez trabalhos. Posteriormente, em um estudo detalhado de cada dissertação e tese, apenas seis trabalhos responderam aos questionamentos que se constituem dados para o alcance dos objetivos propostos, conforme o disposto no Quadro 1. 


\begin{tabular}{|c|c|c|c|c|c|c|}
\hline 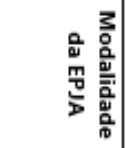 & 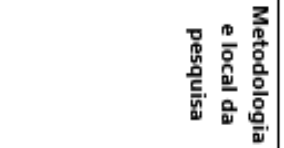 & 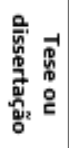 & 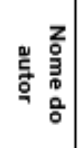 & 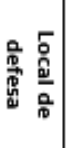 & 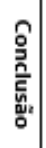 & 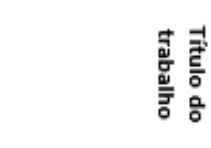 \\
\hline 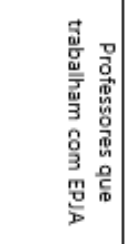 & 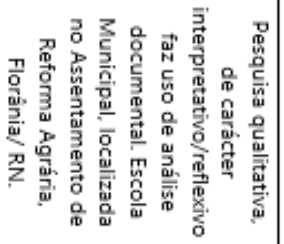 & 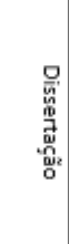 & 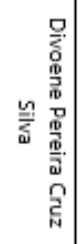 & $\begin{array}{l}\frac{z}{u} \\
\frac{u}{1} \\
\frac{D}{z} \\
z\end{array}$ & $\frac{N}{O}$ & 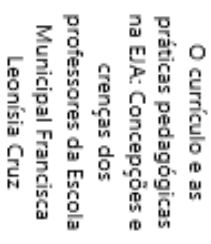 \\
\hline 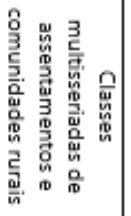 & 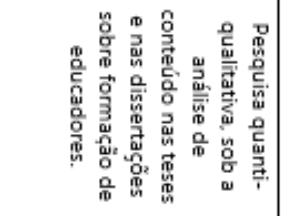 & 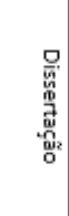 & 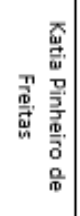 & 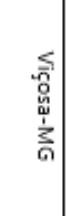 & $\underset{\mathrm{w}}{\mathrm{o}}$ & 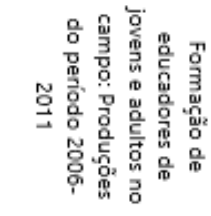 \\
\hline 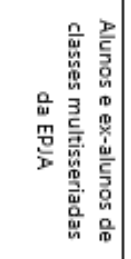 & 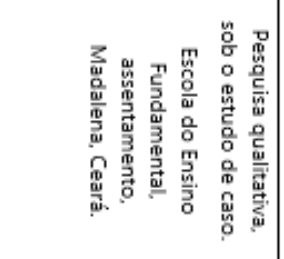 & 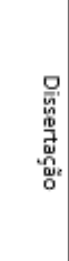 & 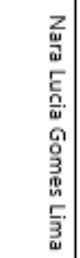 & 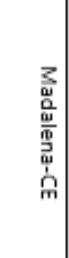 & $\frac{O}{O}$ & 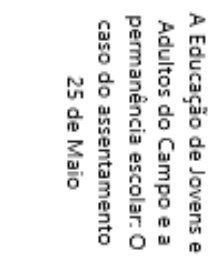 \\
\hline 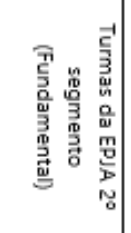 & 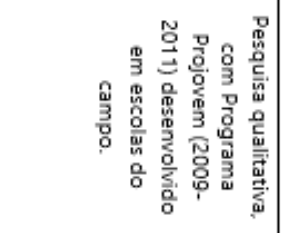 & 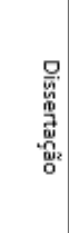 & 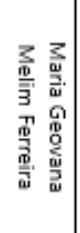 & 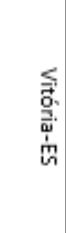 & $\begin{array}{c}0 \\
\stackrel{a}{v} \\
v\end{array}$ & 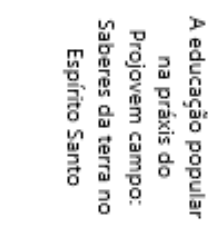 \\
\hline 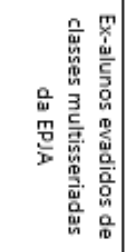 & 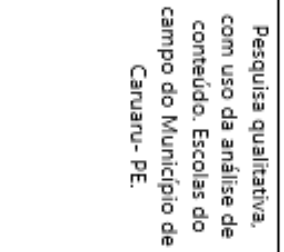 & 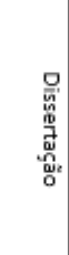 & 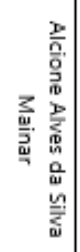 & 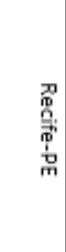 & $\begin{array}{l}0 \\
0 \\
v\end{array}$ & 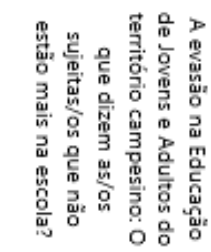 \\
\hline 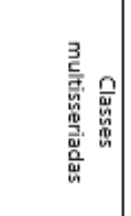 & 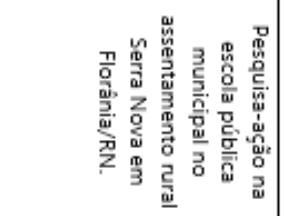 & 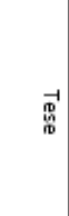 & 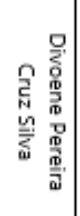 & 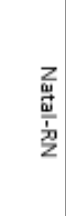 & $\begin{array}{l}\mathrm{y} \\
\mathrm{O} \\
\mathrm{a}\end{array}$ & 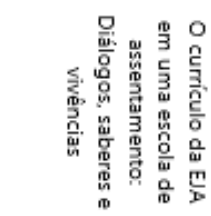 \\
\hline
\end{tabular}




\begin{tabular}{|c|c|c|c|}
\hline 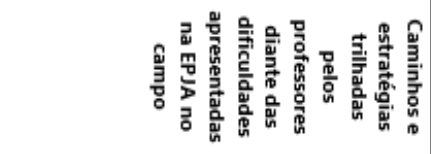 & 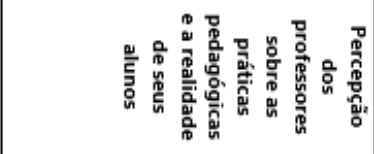 & 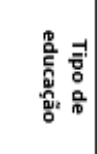 & 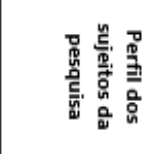 \\
\hline 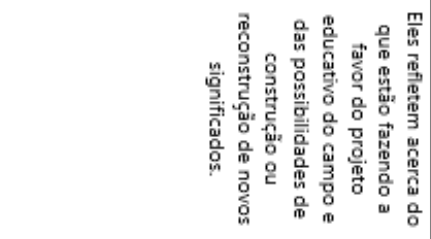 & 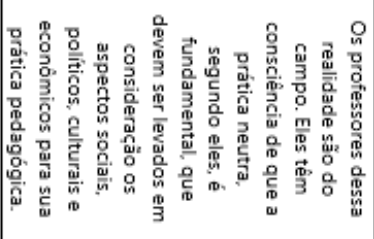 & 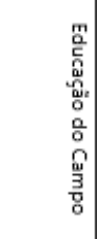 & 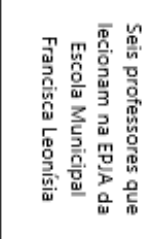 \\
\hline 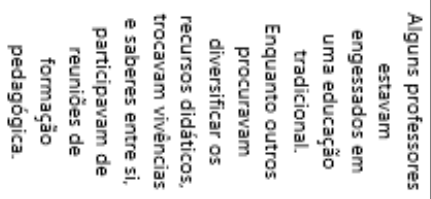 & 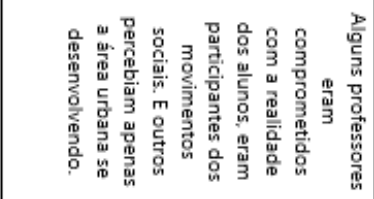 & 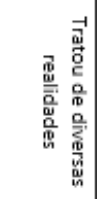 & 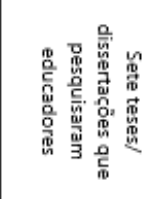 \\
\hline 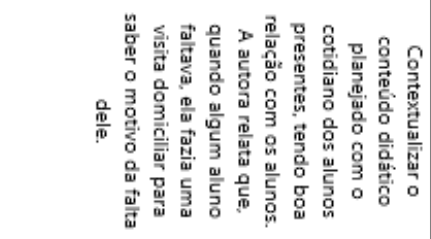 & 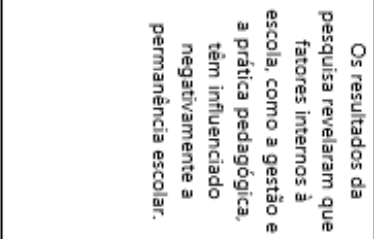 & 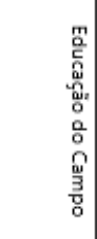 & 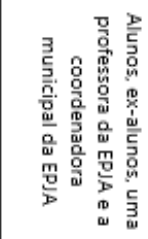 \\
\hline 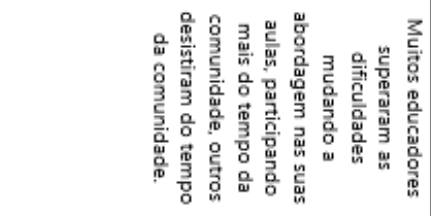 & 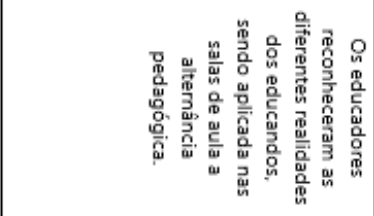 & 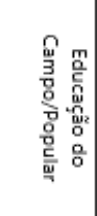 & 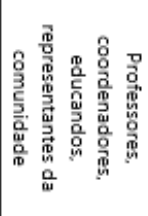 \\
\hline 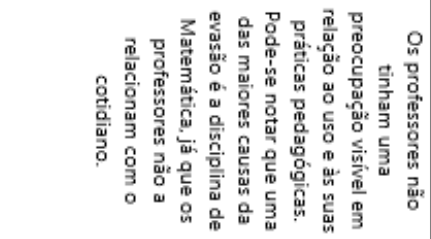 & 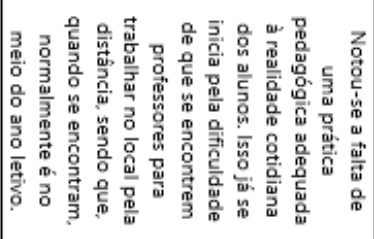 & 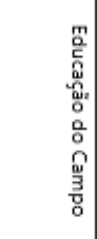 & 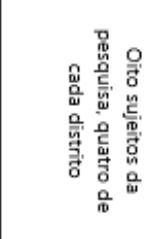 \\
\hline 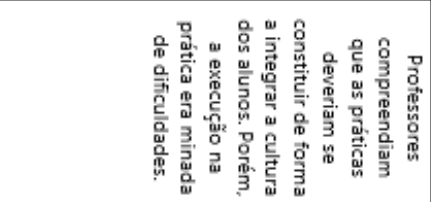 & 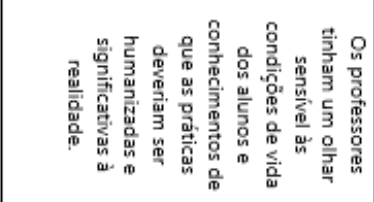 & 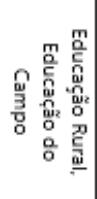 & 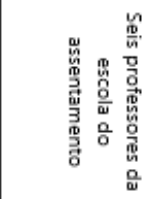 \\
\hline
\end{tabular}




\section{ABORDAGEM DAS PRÁTICAS PEDAGÓgICAS DOS PROFESSORES DA EDUCAÇÃO DE PESSOAS JOVENS E ADULTAS NO CAMPO: $O$ que dizem as teses e as dissertações (2010-2019)}

\section{Caracterização das teses e das dissertações}

Ao se analisar o Quadro 1, de forma a visualizar, de maneira geral, essas teses e dissertações, verifica-se que os textos, em sua maioria, são dissertações (cinco) e apenas uma tese, demonstrando dois pontos que possibilitam que se indague sobre como o tema é pouco pesquisado e, quando o é, sobressai-se em pesquisas de mestrado. É relevante também retratar que os trabalhos foram realizados em cinco estados do Brasil (Minas Gerais, Ceará, Espírito Santo, Pernambuco e Rio Grande do Norte). No último caso, trata-se de uma dissertação e uma tese da mesma autora (SILVA, 2012, 2016).

Diante dos títulos selecionados, observou-se que as dissertações e a tese foram produzidas por pessoas do gênero feminino. Também foi possível verificar que poucos são os trabalhos que trazem em seus resumos um guia para o leitor, de forma completa, que leve a um direcionamento para a temática proposta. Entretanto, fez-se refletir que, em linha geral, os títulos abordam a prática docente da EPJA no campo, de forma a ser analisada em uma perspectiva de saberes e vivências.

As produções selecionadas se diferenciam em suas linhas de pesquisas e em seus casos estudados, revelando, por exemplo, que as práticas dos professores são vivenciadas de forma pontual, como foi visto no trabalho de Freitas (2013). Ela analisou sete pesquisas sobre formação de professores da EPJA no campo, do período de 2006 a 2011, percebendo como a essa formação docente não é específica à realidade em que estão atuando, o que afeta a prática desses educadores, além de possibilitar a reflexão sobre a prática delineada dentro das vivências e das experiências.

Nesse entremeio, a dissertação de Ferreira (2015) proporciona um olhar localizado sobre as práticas dos professores em um programa ofertado em assentamentos. Ela apresenta questões que 
também são citadas nas demais dissertações, como: a formação inicial; a dificuldade de recursos financeiros e estruturais; a necessidade de práticas sensíveis, emancipadoras e significativas. A única tese selecionada para fins deste trabalho foi da autoria de Silva (2016). Ela trouxe, de forma majoritária, a discussão sobre as práticas dos professores da EPJA no campo, apesar de o tema ser inclinado à observância do currículo. Entretanto, como a pesquisa é uma análise das falas de seis professores atuantes em tal realidade, as informações sobre as práticas revelam questões relevantes para o alcance do objetivo deste artigo.

Outro fator que se constata, nas dissertações e na tese é o tipo de abordagem metodológica utilizada. Viu-se que elas usam a perspectiva qualitativa de pesquisa. Essa faz parte de quase todas as metodologias, exceto a de Freitas (2013), com pesquisa quantiqualitativa. Entretanto, elas se diferenciam nos seus diferentes tipos de atuação, como, por exemplo, na abordagem colaborativa, da autora Silva (2016), e na autora Ferreira (2015), que se utilizou da análise bibliográfica.

As pesquisas dessas dissertações e dessa tese foram realizadas em assentamentos e comunidades rurais, nas classes multisseriadas e no segundo segmento EPJA (Ensino Fundamental). Teve-se como abordagem educacional, na grande maioria, a Educação do Campo. As pessoas participantes se constituem em professores, coordenadores, alunos, ex-alunos, representantes de comunidades e de movimentos sociais, com complementação por meio de análise bibliográfica, como no caso da autora Ferreira (2015).

\section{As práticas pedagógicas dos professores da EPJA no campo: o que dizem as dissertações e as teses}

Reconhecer a importância das práticas pedagógicas como um fator essencial no ensino-aprendizagem, quando se constituem inovadoras, reflexivas e integradoras de uma realidade com conhecimentos e saberes, é fundamental para a efetivação da permanência dos alunos no âmbito educacional, da formação integral, da transformação social, cognitiva e crítica, que habilite a ação do aluno na realidade vigente, principalmente quando se trata 
do público da EPJA, que precisa ser respeitado por suas singularidades, seu cotidiano, sua cultura e seus saberes e que não terminou os ciclos da Educação Básica, ou mesmo nem iniciou, tendo realidades permeadas por limitações e restrições.

O conjunto de produções analisadas suscitam diversas reflexões sobre as práticas pedagógicas de docentes na realidade da Educação de Pessoas Jovens e Adultas no campo. No que tange a essas práticas, um dos principais pontos observados diz respeito à formação dos professores atuantes naquela realidade tão singular, que não tiveram preparo específico para uma prática reflexiva e transformadora. Para Arroyo (2008), quando se trata da formação docente, esse é um dos grandes desafios à educação no campo.

Nesse contexto, a formação inicial do professor se constitui com o desenvolvimento e a atuação os educadores na EPJA. Haddad (2002) afirma que há uma carência de reflexão sobre a EJA nos cursos de formação docente de nível médio, tanto quanto nas universidades e nas pós-graduações, apesar de, em alguns Projetos Pedagógicos de cursos de Pedagogia, já existirem tais debates, mas a maioria ainda não percebe a EPJA como algo fundamental dentro do seu currículo.

Pontua-se que Freitas (2013), Ferreira (2015) e Silva (2016) apresentam esse aspecto como o principal norteador das práticas dos professores, pois se observou uma lacuna que se espelhava na atuação dos docentes nas salas de aulas de pessoas jovens e adultas do campo, caracterizando práticas desconectadas da realidade, pautadas no modelo escolar urbano. Nesse sentido, quando se constitui uma prática inovadora que respeite a realidade vigente, o caso de uma professora entrevistada na pesquisa de Silva (2016), não se atribui à formação, mas à (re)construção realizada no cotidiano da sala de aula, nas vivências e nas experiências.

Entende-se o aprender do professor como um processo de ação-reflexão-ação durante sua prática, que faz e refaz caminhos para proporcionar um espaço de aprendizagem significativa, além do aspecto compromissado que o educador deve ter para possuir uma prática pedagógica de qualidade, que não seja levada pelo comodismo e pelo mecanicismo pedagógico, o que torna um desafio na EPJA. 
Observou-se a problemática da falta de formação específica à atuação dos educadores da EPJA na pesquisa de Ferreira (2015). Ela analisou registros dos educadores do "Projovem: Saberes da Terra", percebendo dificuldades no desenvolvimento das aulas e na falta de conhecimentos sobre as metodologias do projeto (que reivindica um currículo integrador dispondo do tempo na escola e na comunidade - da pedagogia da alternância e dos eixos norteadores -, didáticas significativas e inovadoras para uma eficácia e uma integração na educação no e do campo) que não fizeram parte da formação desses profissionais. Os professores retratavam que "[...] deveriam ter tido formações antes do projeto para facilitar a atuação (p.110)".

Sabemos que um dos determinantes da precariedade da educação do campo é a ausência de um corpo de profissionais que vivam junto às comunidades rurais, que sejam oriundos dessas comunidades, que tenham como herança a cultura e os saberes da diversidade de formas de vida no campo. A maioria das educadoras e educadores vai, cada dia, da cidade à escola rural e de lá volta a seu lugar, a cidade, a sua cultura urbana. Consequentemente, nem tem suas raízes na cultura do campo, nem cria raízes. (ARROYO, 2008, p.169).

Os trabalhos de Silva $(2012,2016)$ e Freitas (2013) tratam do diferencial na ação pedagógica quando o educador, por exemplo, compartilha da mesma realidade rural dos alunos. Nesse caso, os docentes participam de movimentos sociais da luta pelos direitos do campo; constituem-se em um olhar sensível das dificuldades apresentadas pelos alunos; buscam por uma práxis que seja significativa e dialógica com a realidade dos educandos; e atuam no planejamento de estratégias que busquem ultrapassar as dificuldades. Silva (2016, p. 99) afirma:

Nesse sentido, as pesquisas analisadas revelam que o educador que está inserido no contexto social em que atua, apesar de não ter formação acadêmica específica, cria uma capacidade crítica que os permite agir e refletir sobre uma realidade, sendo essa inserção, em conjunto com as experiências nos 
movimentos sociais, o grande diferencial no seu processo de (auto) formação e atuação.

Silva (2016) mostrou, em sua tese, que os professores são do campo, que atuam no campo, o que os faz pensar de forma mais consciente da importância de levar em consideração os aspectos sociais, políticos, culturais e econômicos daquele ambiente para suas práticas pedagógicas. Mas se sabe que essa realidade no ensino da EPJA nem sempre é possível. Na maioria das vezes, são professores do meio urbano que se deslocam para o campo e se deparam com o desafio de elaborar um projeto de educação que seja alinhado à vida cotidiana desses educandos.

Nesses últimos casos, os trabalhos de Freitas (2013) e Silva (2016) revelam que os professores não inseridos na realidade do campo, que residiam em cidades, percebiam a EPJA como um projeto, uma renda extra. Soares, Gionvanetti e Gomes (2005, p. 58) demonstram que a Educação de Jovens e Adultos "[...] nem sempre foi reconhecida como uma modalidade educativa que requer um profissional adequado para o seu exercício". Alguns desses educadores adentravam as salas de aula com um preconceito sobre o perfil do aluno da EJA, fazendo com que isso perpassasse pela ação docente, o que resultava em uma prática "engessada" e mecânica e, como os próprios sujeitos da pesquisa relataram em suas falas, em um "repasse dos conteúdos".

É importante ressaltar que, segundo Azevedo (2010), a dificuldade da prática docente não se restringe aos recursos didáticos, à estrutura física da escola, ao aluno, mas uma das maiores dificuldades se encontra nas classes multisseriadas, por seu caráter heterogêneo, diversificado e plural.

Refletindo em uma visão geral das práticas pedagógicas dos educadores relatados nas pesquisas, observou-se que é pequeno o grupo que procura perpassar as dificuldades que norteiam sua ação docente em uma realidade tão particular e desafiadora. Freitas (2013), Lima (2014), Ferreira (2015) e Silva (2016) mostram, em suas pesquisas, que os professores, apesar dos desafios, realizavam práticas que contribuiriam para uma real formação dos alunos, elevavam os alunos como protagonistas, bem como suas realidades, procurando romper as dificuldades, participando de formações, 
trocas de experiências com outros educadores, planejamento reflexivo e crítico, busca por melhores recursos didáticos.

$\mathrm{Na}$ tese de Lima (2014), ficam evidentes diversos fatores que permeiam tal permanência dos alunos da EJA na escola e que eles não somente transpassam na prática pedagógica do professor dentro da sala de aula, mas também são influenciados por questões externos à sala de aula e à própria escola, como a gestão escolar, a coordenação pedagógica, os outros professores e as gestões municipais do Estado. O fato traz a reflexão de que a prática pedagógica eficaz não somente está relacionada ao professor dentro da sala de aula e do âmbito escolar em geral, mas permeia toda a dimensão da prática social e é alcançada e influenciada por diversos fatores.

Silva (2016) pontua, de forma veemente, com as falas dos(as) professores(as) que participavam de sua pesquisa, a questão do alinhamento entre currículo e práticas pedagógicas como âncora em todo o processo educacional, fazendo-se como um quadro impeditivo para uma ação docente crítica, livre, com respaldo curricular e apoio político. Isso porque o currículo da escola era feito pela Secretaria de Educação de Florânia-RN, totalmente pautado em um modelo de escola regular e desconectado da realidade em que a instituição escolar se localizava, constituindo-se em uma educação rural, ao mesmo tempo em que os professores tentavam implementar práticas transformadoras, uma educação no e do campo. Isso diverge de um dos traços fundamentais da identidade do movimento por uma Educação do Campo, que é

[...] a luta do povo do campo por políticas públicas que garantam o seu direito à educação e a uma educação que seja no e do campo. No: o povo tem direito a ser educado no lugar onde vive. Do: o povo tem direito a uma educação pensada desde o seu lugar e com a sua participação, vinculada à sua cultura e às suas necessidades humanas e sociais (CALDART, 2011, p. 149-150).

Perceber que o público da EPJA do campo é diferenciado e pode não se enquadrar nas mesmas necessidades do público da cidade é fundamental na construção do currículo. O educador precisa 
enxergar a importância de alinhar suas práticas à identidade individual e social dos educandos do campo, de modo que o processo de ensino-aprendizagem seja pautado nas necessidades, nas vivências, no respeito aos saberes, alinhando os conhecimentos dos alunos aos conteúdos (FREIRE, 1997).

\section{CONSIDERAÇÕES FINAIS}

Sabe-se que a Educação de Pessoas Jovens e Adultas tem suas raízes na Educação Popular, no MST. Esses foram movimentos de muitas lutas, resultando na escolarização da EPJA. No entanto, sob a institucionalização do Estado, as escolas restringiram, muitas vezes, seus alunos à sala de aula, sendo eles submetidos às práticas de ensino tradicionais, o que foi combatido, em grande parte, por Paulo Freire, considerado pai da Educação de Pessoas Jovens e Adultas. Foi pensando nessas formas de institucionalização da EPJA que se objetivou investigar as práticas pedagógicas de professores da Educação de Pessoas Jovens e Adultas do campo em teses e dissertações do período de 2010 a 2019.

As análises das dissertações e da tese possibilitaram investigar as práticas pedagógicas dos professores da EPJA pelas vertentes das dificuldades e das facilidades no desempenho dessa modalidade de ensino, das políticas públicas que a norteiam, bem como da sua fundamentação na formação inicial do educador. Esses cursos de formação podem trazer para a EPJA o reconhecimento da necessidade de revisitação curricular das escolas do campo, de modo que o currículo atenda às necessidades desse público tão singular.

As dissertações e a tese discutidas mostraram as necessidades específicas e as dificuldades enfrentadas na EPJA, principalmente porque somente alguns professores estavam comprometidos com as realidades dos alunos, sendo esses educadores participantes/ simpatizantes dos movimentos sociais, enquanto outros se pautavam por práticas pedagógicas tradicionais, em que os educandos e as suas realidades eram percebidos pela lógica urbana de desenvolvimento.

Há de se salientar, ainda, que outros professores compreendiam que suas práticas deveriam se constituir de forma a integrar a vida comunitária, a cultura e os saberes dos alunos, mas a 
sua execução era minada de dificuldades, sendo que a superação se dava em um processo lento, já que se tratava de mudanças no currículo, na estrutura escolar e no apoio governamental.

Portanto, observou-se, nessas dissertações e nessa tese, que as práticas pedagógicas de professores da EPJA se constituem em realidades em que as condições das escolas são precárias de recursos didáticos, com oferta aligeirada e professores que não portavam formação específica e necessária. Em algumas dessas instituições, as práticas pedagógicas eram constantemente mudadas e repensadas para melhor superar as muitas dificuldades, valorizando o saber da experiência, de modo que os alunos se enxergavam como protagonistas, sendo tais práticas integradoras com a realidade, visando ao desenvolvimento do educando.

\section{REFERÊNCIAS}

ARROYO, M. G.; CALDART, R. S.; MOLINA, M. C. Por uma educação do campo. 3. ed. Petrópolis: Vozes, 2008.

ARROYO, M. G. Políticas de formação de educadores(as) do campo. Caderno Cedes, Campinas, v. 27, n. 72, p. 157-176, maio/ago. 2007. Disponível em: http://www.scielo.br/pdf/ccedes/v27n72/a04v2772.pdf. Acesso em: 16 jan. 2021.

AZEVEDO, M. A. de. Avaliação do programa escola ativa como política pública para escolas do campo com turmas multisseriadas: a experiência em jardim do SERIDÓ/RN (1998 2009). Natal/RN: UFRN, 2010.

BARDIN, L. Análise de conteúdo. Lisboa: Edições 70, 2004. BELUZO, M. F.; TONIOSO, J. P. O mobral e a alfabetização de adultos: considerações históricas. Cadernos de Educação: Ensino e Sociedade, v. 2, n. 1, 2015.

BRASIL. Lei no 9.394, 20 de dezembro de1996. Estabelece as diretrizes e bases da Educação Nacional, Diário Oficial da União, Brasília, DF, 23 dez. 1996. Disponível em: 
http://www.planalto.gov.br/ccivil_03/LEIS/L9394.htm. Acesso em: 13 abr. 2021.

BRASIL. Conselho Nacional de Educação. Câmara de Educação Básica. Diretrizes Operacionais para a Educação Básica nas Escolas do Campo. Resolução no 1 de 03 de abril de 2002. Institui Diretrizes Operacionais para a Educação Básica nas Escolas do Campo. 2002.

BRITTO, L. P. L. Contra o consenso: cultura escrita, educação e participação. Campinas/SP: Mercado de letras, 2003.

CALDART, R. S. Por Uma Educação do Campo: traços de uma identidade em construção. In: ARROYO, M. G.; CALDART, R. S.; MOLINA, M. C. (Orgs.). Por uma educação do Campo. 5. ed. Petrópolis, RJ: Vozes, 2011.

CODO, W.. Educação: carinho e trabalho. Rio de Janeiro: Vozes, 1999.

DEMO, P. Universidade, aprendizagem e avaliação: horizontes reconstrutivos. Porto Alegra: Medicação, 2004.

FERREIRA, N. S. de A.. As pesquisas denominadas "estado da arte". Educação \& Sociedade, São Paulo, ano 23, n. 79, p.257-272, ago. 2002. Disponível em: http://www.scielo.br/pdf/es/v23n79/10857.pdf Acesso em 25 de mai. 2020.

FERREIRA, M. G. M. A educação popular na práxis do Projovem campo: Saberes da terra no Espírito Santo. Dissertação (Mestrado em Educação) - Universidade Federal do Espírito Santo, Vitória, 2015.

FREIRE, P. Pedagogia da autonomia: saberes necessários à prática educativa. Rio de Janeiro: Paz e Terra, 1997.

FREITAS, M. C. de; BICCAS, M. de S. História social da educação no Brasil. (1926-1996). São Paulo/SP: Cortez, 2009.

FREITAS, K. P. de. Formação de educadores de Jovens e Adultos no Campo: Produções do período 2006-2011. Dissertação (Mestrado em Educação) - Universidade Federal de Viçosa. Viçosa MG. 2013. 
GADOTTI, M. Alfabetizar e Politizar: Angicos, 50 anos depois.

Revista de Informação do Seminário - RISA, Angicos, RN, v. 1, n. 1, p. 47-67, jan./jun. 2013. Edição Especial. Disponível em: http://periodicos.ufersa.edu.br/revistas/index.php/risa/article/view/3 150. Acesso em: 06 de mar. de 2020.

GHEDIN, E. Educação do Campo: epistemologia e práticas. 1.ed. São Paulo: Cortez, 2012.

HADDAD, S. Educação de Jovens e Adultos no Brasil: 1986-1998. Brasília: Ministério da Educação e Cultura, 2002.

INEP - INSTITUTO NACIONAL DE ESTUDOS E PESQUISAS

EDUCACIONAIS ANÍSIO TEIXEIRA. Censo da Educação Básica 2018. 2019. Disponível em: Disponível em:

http://download.inep.gov.br/educacao_basica/censo_escolar/resum os_tecnicos/resumo_tecnico_censo_educacao_basica_2018.pdf. Acesso em: 10 jul. 2020.

IPEA - INSTITUTO DE PESQUISA ECONÔMICA APLICADA. Atlas do Desenvolvimento Humano do Brasil 2003. Disponível em: http://www.ipea. gov.br. Acesso em 15 de ago. 2020.

LEAL, T. F.; ALBUQUERQUE, E. B. C. de; MORAIS, A. G. de. Avaliação e aprendizagem na escola: a prática pedagógica como eixo da reflexão. Construir Notícias, edição 43, 2007. Disponível em: https://www.construirnoticias.com.br/avaliacao-e-aprendizagem-naescola-a-pratica-pedagogica-como-eixo-da-reflexao/. Acesso em: 23 de abr. 2021.

LIMA, N. L. G. A educação de Jovens e adultos do Campo e a permanência escolar: $O$ caso do assentamento 25 de maio.

Dissertação (Mestrado em Educação) - Universidade Federal do Ceará, Madalena - CE, 2014.

LÜDKE, M.; ANDRÉ, M. E. D. A. Pesquisa em educação: abordagens qualitativas. São Paulo: EPU, 1986.

MELO, M. V. Três décadas de pesquisa em Educação Matemática: um estudo histórico a partir de teses e dissertações. Dissertação (Mestrado em Educação) - Universidade Estadual de Campinas, Campinas. 2006. 
MONTEIRO, A. Reflexões sobre a organização do trabalho pedagógico: os "tempos" na educação do campo. In: BRASIL. Secretaria de Educação Básica. Diretoria de Apoio à Gestão Educacional. Pacto Nacional pela Alfabetização na Idade Certa: Educação Matemática do Campo/ Ministério da Educação, Secretaria de Educação Básica, Diretoria de Apoio à Gestão Educacional. Brasília, DF: MEC, SEB, 2014.

ROMANOWSKI, J. P.; ENS, R. T. As pesquisas denominadas do tipo "estado da arte" em educação. Diálogo Educ., Curitiba, v. 6, n. 19, p. 37-50, set./dez. 2006. Disponível em:

http://alfabetizarvirtualtextos.files.wordpress.com/2011/08/aspesquisasdenominadas-do-tipo-estado-da-arte-emeducac3a7c3a3o.pdf Acesso em 25 de mai. 2020.

SHEIBE, L. Valorização e formação dos professores para a Educação Básica: questões desafiadoras para um novo Plano Nacional de Educação. Revista Educ. Soc., Campinas, v. 31, n. 112, p. 981-1000, jul.-set. 2010. Disponível em: http://www.cedes.com.br. Acesso em: 20 de janeiro de 2020.

SILVA, M. R. Causas e Consequências da evasão escolar na Escola Normal Estadual Professor Pedro Augusto de Almeida -

Bananeiras/PB. Biblioteca Virtual. João Pessoa, 2011. Disponível em http://biblioteca.virtual.ufpb.br/files/causas_e_consequancias_da_eva sao_escolar_na_escola_normal_estadual_professor_pedro_augusto_d e_almeida_a_bananeias_pb_1343397993.pdf. Acesso em: 18 de jan. 2021.

SILVA, D. P. C. S. O Currículo e as Práticas Pedagógicas na EJA:

Concepções e Crenças dos professores da Escola Municipal Francisca Leonísia Cruz. Dissertação (Mestrado em Educação) Universidade Federal do Rio Grande do Norte, Natal. 2012.

SILVA, D. P. C. S. O currículo da EJA em uma escola de assentamento: Diálogos, Saberes e Vivências. Tese de doutorado. Natal-RN, 2016. 
SOARES, L. J. G.; GIOVANETTI, M. A.G. de C.; GOMES, N. L. (Org.)

Diálogo na educação de jovens e adultos. Belo Horizonte:

Autêntica, 2005.

THERRIEN, J.; DAMASCENO, M. N. Educação e Escola no Campo.

Campinas: Papirus, 1993.

VEIGA, I. P. A. A Prática Pedagógica do Professor de Didática. 2.

Ed. Campinas, Papirus, 1992.

ZANETTI, M. A.; SCHWENDLER, S. F. Formação de Educadoras e

Educadores: O planejamento na alfabetização de jovens e adultos.

Curitiba/PR: Editora Gráfica Popular, 2003.

Submetido em: Julho/ 2021.

Aceito em: Agosto/ 2021. 